Article

\title{
Analyses of the Temperature Field of a Piezoelectric Micro Actuator in the Endoscopic Biopsy Channel
}

\author{
Pancheng Zhu®, Hanmin Peng *®D and Jianzhi Yang \\ State Key Lab of Mechanics and Control of Mechanical Structures, Nanjing University of Aeronautics \& \\ Astronautics, Nanjing 210016, China; zhupancheng@nuaa.edu.cn (P.Z.); yangjianzhi@nuaa.edu.cn (J.Y.) \\ * Correspondence: penghm@nuaa.edu.cn
}

Received: 23 September 2019; Accepted: 19 October 2019; Published: 23 October 2019

Featured Application: This paper describes the thermal analyses of a piezoelectric micro actuator in an endoscopic biopsy to solve the overheating problem in the narrow space. The proposed method can be used for the operation of the piezoelectric micro actuator at a safe level, in order to achieve drive control and drug permeation promotion of precise dosing devices in the endoscopic biopsy channel.

\begin{abstract}
Micro actuators have been used to realize the arrival of digestive tract lesions for the local targeted application of drugs in endoscopes. However, there still exists a key safety issue that casts a shadow over the practical and safe implementation of actuators in the human body, namely an overheated environment caused by actuators' operation. Herein, with the aim of solving the temperature rising problem of a piezoelectric micro actuator operating in an endoscopic biopsy channel (OLYMPUS, Tokyo, Japan), a thermal finite element method (FEM) based on COMSOL Multiphysics software is proposed. The temperature distribution and its rising curves are obtained by the FEM method. Both the simulated and experimental maximum temperatures are larger than the safety value (e.g., $42{ }^{\circ} \mathrm{C}$ for human tissues) when the driving voltage of the actuator is $200 \mathrm{~V}_{\mathrm{pp}}$, which proves that the overheating problem really exists in the actuator. Furthermore, the results show that the calculated temperature rising curves correspond to the experimental results, proving the effectiveness of this FEM method. Therefore, we introduce a temperature control method through optimizing the duty ratio of the actuator. In comparison with a $100 \%$ duty ratio operation condition, it is found that a $60 \%$ duty ratio with a driving voltage of $200 \mathrm{~V}_{\mathrm{pp}}$ can more effectively prevent the temperature rising issue in the first $3 \mathrm{~min}$, as revealed by the corresponding temperatures of 44.4 and $41.4{ }^{\circ} \mathrm{C}$, respectively. When the duty ratio is adjusted to $30 \%$ or less, the temperature rise of the actuator can be significantly reduced to only $36.6^{\circ} \mathrm{C}$, which is close to the initial temperature $\left(36.4^{\circ} \mathrm{C}\right)$. Meanwhile, the speed of the actuator can be well-maintained at a certain level, demonstrating its great applicability for safe operation in the human body.
\end{abstract}

Keywords: piezoelectric micro actuator; endoscopic biopsy channel; thermal analyses; temperature rise control methods; finite element method (FEM)

\section{Introduction}

Over the past decades, the development of micro actuators and motors for providing an efficient approach to realizing the arrival of digestive tract lesions has trigged enormous interest from both academia and industry [1-4]. This is because even making use of modern advanced minimally invasive surgery, such as Endoscopic Submucosal Dissection (ESD), negative consequences, including perforation [5] and postoperative bleeding, may be induced [6,7], thus posing a threat to the patient's life. It has been found that employing endoscopic hemostatic forceps or other surgical methods can 
temporarily stop bleeding; however, over $30 \%$ of patients still suffer from postoperative bleeding [8-10]. In addition, it should be noted here that ESD treatment is strictly prohibited for patients with blood clotting disorders and blood diseases [11-13]. On the other hand, chemotherapy-targeted drugs have been demonstrated to be effective for curing major gastrointestinal diseases [14,15]. However, the traditional oral approach for taking chemotherapy-targeted drugs is prone to causing systemic allergic reactions and serious side effects $[16,17]$. Therefore, there is an urgent need to develop a new and efficient approach to realizing the arrival of digestive tract lesions for local targeted applications of drugs in endoscopes.

Currently, for the practical and safe operation of micro actuators inside the human body, two main issues still exist, including the lack of linear motion and the temperature increase when operating in the endoscopic biopsy channel [18]. In particular, the temperature rising issue induced by the thermal effect of actuators can cause overheating, giving rise to histologic damage [19-21], i.e., burns and tissue necrosis, thus making it difficult to realize long-term safe operation inside the human body. Due to their distinguished features of a high precision [22,23], quick response [24,25], simple structure [26,27], and miniature size $[28,29]$, piezoelectric actuators have emerged as one of the promising candidates. Our recent work demonstrated the capability of a small-sized piezoelectric actuator (diameter $3 \mathrm{~mm}$ ) being operated in an endoscopic biopsy channel (OLYMPUS, Tokyo, Japan) for releasing targeted drugs [30]. However, the operation of a piezoelectric actuator in the endoscopic biopsy channel can also yield an elevated temperature of over $42{ }^{\circ} \mathrm{C}$, which has been suggested to be the safe temperature limit, resulting in a temperature rising problem, as mentioned above. Therefore, exploring an effective approach to address this issue still remains a challenge for their practical and commercial application.

Herein, in this work, with the aim of preventing the temperature issue of our piezoelectric actuator, we propose a thermal finite element method (FEM) based on COMSOL Multiphysics software to achieve thermal analyses. Additionally, systematic work is performed to study the effect of the duty ratio on the temperature and speed of the actuator because, when the actuator is installed in the endoscope, the permanent magnet orbit is ground to a thickness of $0.35 \mathrm{~mm}$, and its magnetic induction intensity is $43 \mathrm{mT}$, making it difficult to decrease the temperature by decreasing the driving voltage amplitude (the minimum driving voltage is $200 \mathrm{~V}_{\mathrm{pp}}$ ). Therefore, only modulating the duty ratio of the actuator is applicable to control the temperature rises of the actuator. According to the theoretical analysis and experimental results, it is found that a $60 \%$ duty ratio with a driving voltage of $200 \mathrm{~V}_{\mathrm{pp}}$ can more effectively decrease the temperature rise from $44.4{ }^{\circ} \mathrm{C}$ to $41.4^{\circ} \mathrm{C}$ in the first $3 \mathrm{~min}$. Moreover, the temperature of the actuator is significantly reduced to around $36.6{ }^{\circ} \mathrm{C}$ when the duty ratio is modulated to less than $30 \%$. Furthermore, the speed of the actuator can be well-held at a certain level, proving its safe usability for operation in the endoscopic biopsy channel.

\section{Material and Methods}

\subsection{Micro Piezoelectric Actuator in the Endoscopic Biopsy Channel}

To ensure actuator operation in the endoscopic biopsy channel, a light-weight surface milli-walker based on piezoelectric actuation was designed and reported in our recent research [30]. Although its overall size met the size limit of an endoscope, the actuator needs a pre-pressure track, which was provided by an electromagnet and corresponding power supply wire in actual installation, and the resultant overall size turned out to be too large to be integrated into the biopsy channel of an endoscope. Therefore, a permanent magnet orbit instead of an electromagnet is used to provide the magnetic field for the actuator in this paper. Despite the permanent magnet size, whose thickness is far smaller than that of an electromagnet, it still has a high magnetic induction intensity to provide enough pre-pressure, making it suitable for application in the endoscopic biopsy channel, as shown in Figure 1a. In addition, the overall size of the actuator is miniaturized to $4.5 \mathrm{~mm} \times 1.5 \mathrm{~mm} \times 1.5 \mathrm{~mm}$ (length $\times$ width $\times$ height) and its driving frequency is $10.4 \mathrm{kHz}$ in this paper. The actuator weight is $0.063 \mathrm{~g}$, in which the size of the thickness is $0.2 \mathrm{~mm}$ and the size of the piezoelectric ceramic is $1.5 \mathrm{~mm} \times 0.2 \mathrm{~mm} \times 3 \mathrm{~mm}$, as seen in 
Figure $1 \mathrm{~b}$. Moreover, to enable the linear motion of the actuator in the endoscopic biopsy channel, the permanent magnet orbit is polished by sand paper to achieve a thickness of $0.35 \mathrm{~mm}$ and an effective working distance of $10 \mathrm{~mm}$, and the object is shown in Figure 1c.

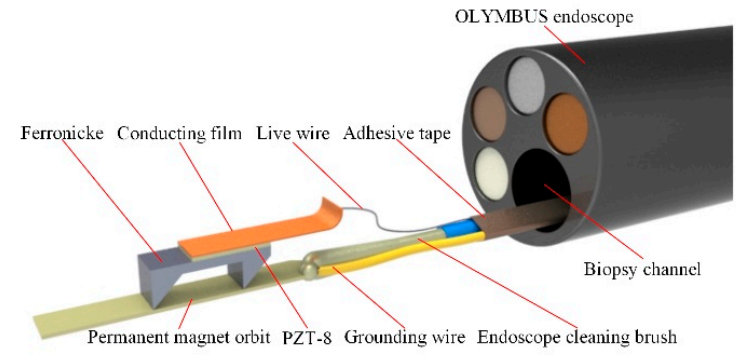

(a)

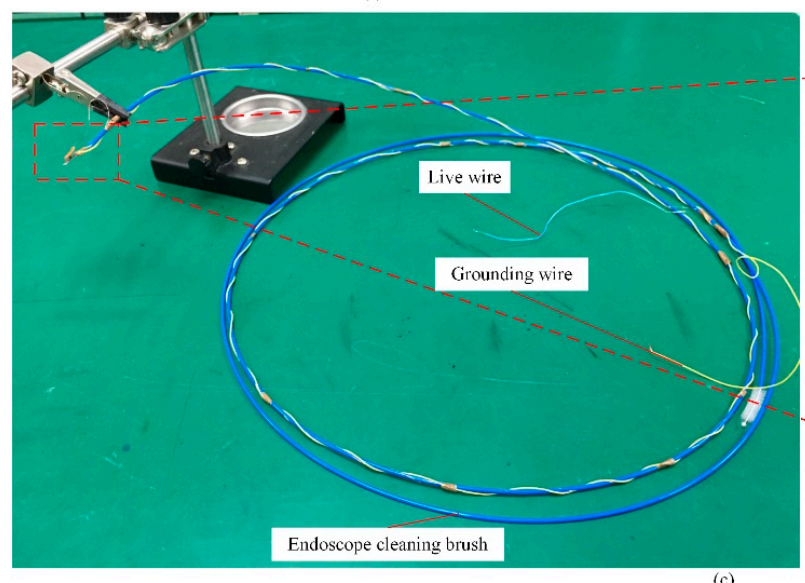

(c)

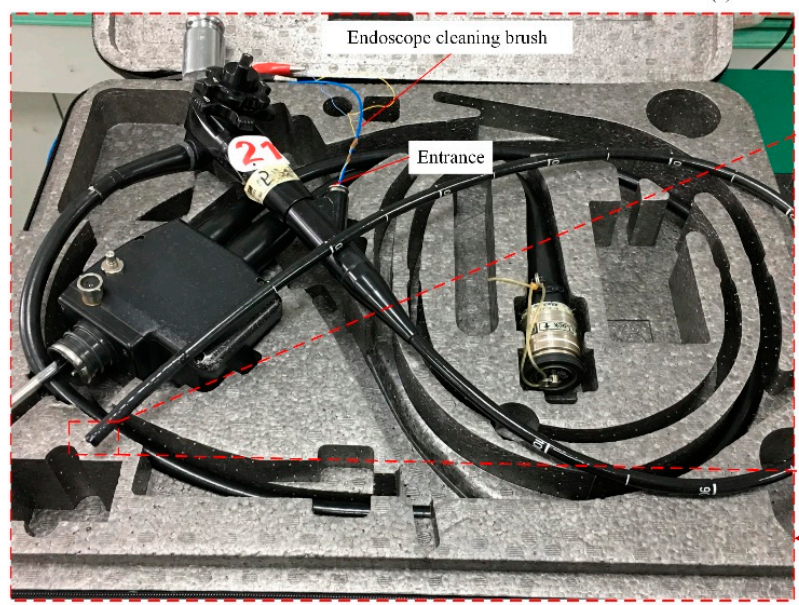

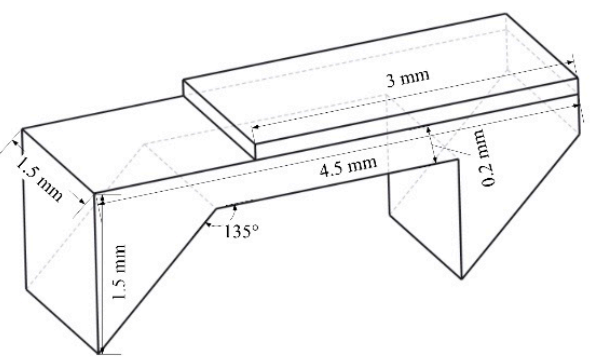

(b)
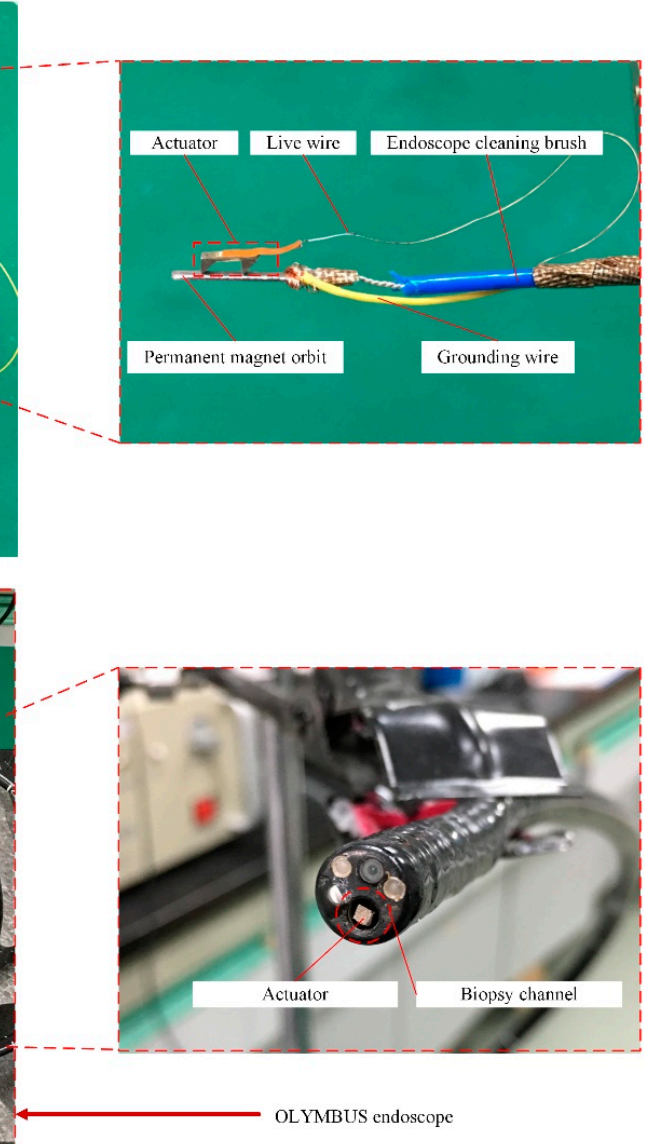

Figure 1. Method of installing the piezoelectric actuator in the endoscopic biopsy channel: (a) the schematic diagram of the piezoelectric actuator; (b) the dimensions of the actuator; (c) the actuator with an endoscope cleaning brush; and (d) the actuator in the biopsy channel.

Generally, the biopsy forceps, needles, and other medical consumables of an endoscope that can move in the endoscopic biopsy channel during surgery are installed with the help of a cleaning brush. In this work, we also employed the cleaning brush to install the actuator and permanent magnets in the endoscopy and realize their combination. The schematic diagram is shown in Figure 1a. The cleaning brush was modified to remove the hair brush of its head and use it as a guide line. Then, the permanent magnet orbit was fixed at the end of the cleaning brush using adhesive tape and the actuator was absorbed on the orbit by the magnetic field. After that, two wires were also fixed on the 
cleaning brush to ensure that the driving voltage could be applied outside. As described above, the actuator system could be installed in the endoscope biopsy channel as a whole, as shown in Figure 1c.

The installation steps of the actuator and permanent magnet orbit in the endoscopic biopsy channel are as follows:

1. Put the actuator on the permanent magnet orbit and fix the actuator through the magnetic field, making it unable to fall off during the installation process;

2. Insert the guide line from the entrance of the biopsy channel. During the installation process, the cleaning brush and the actuator must be inserted under a smooth condition;

3. Ensure the bending angle of the endoscope is not too large to avoid damage to the actuator and permanent magnet orbit when the actuator passes through the bending part of the endoscope;

4. When removing the actuator after use, it should be pulled out from the entrance of the biopsy channel slowly and lightly to prevent the actuator from falling off the track and leaving the endoscope during the pulling process.

It should be noted here that due to the thickness of the permanent magnet orbit being only $0.35 \mathrm{~mm}$, it is easy to break under collision, and thus, special attention should be paid to the installation process. Using the aforementioned steps, the actuator system and its supporting cleaning brush were successfully installed in the endoscopic biopsy channel, as shown in Figure $1 \mathrm{~d}$.

\subsection{Measurement Methods}

To enable the safe movement of the actuator in the endoscopic biopsy channel, heat should be controlled to a certain extent $\left(\leq 42^{\circ} \mathrm{C}\right)$. A FOTRIC thermal imaging camera $(226 \mathrm{~s})$ was used here to witness the temperature rise of the actuator in the endoscopic biopsy channel with a measurement accuracy of $2{ }^{\circ} \mathrm{C}$, which was obtained from ZXF Laboratories (Dallas, TX, USA). Additionally, a thermostat (DHG 303-0) was used to mimic a body temperature of $37 \pm 1{ }^{\circ} \mathrm{C}$ (the errors come from thermal convection in the air) on the surface of the endoscopic channel, which was obtained from Huyue Co., Ltd. (Yiwu, Zhejiang province, China). In the experiments, the actuator with the endoscopic biopsy channel was installed in the thermostat by adhesive tape, as shown in Figure 2 . The maximum temperature of the front end of the actuator in the endoscopic biopsy channel was measured by the thermal imaging camera with the minimum infrared resolution $(384 \times 288$ pixels), which may cause heat damage to the human body.
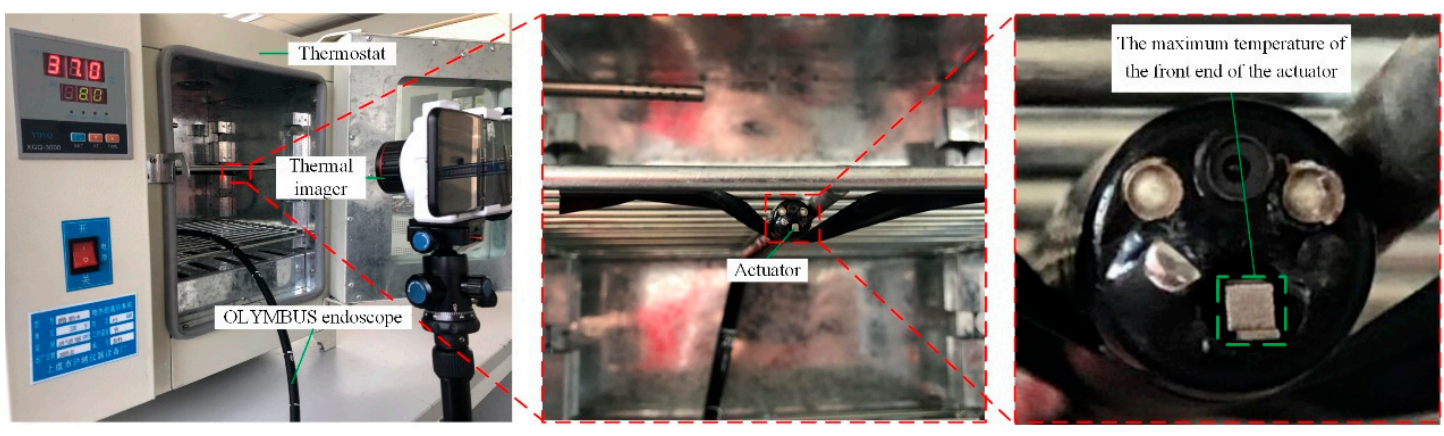

Figure 2. Experimental method of measuring temperature rises of the actuator in the biopsy channel.

\section{Temperature Field Model}

\subsection{Assumptions}

In this section, we use the FEM model built in COMSOL Multiphysics software to analyze the temperature field. The following assumptions are made for the temperature field model of the device:

(1) The voltage applied to the actuator is constant, and the environmental temperature and heat-transfer coefficients are invariable; 
(2) Heat energy generated by the friction loss is ignored because the actuator's movement time is short and it vibrates in the same position at the rest time. Therefore, the mechanical loss and dielectric loss are considered the main sources of heat energy;

(3) Heat energy generated by the mechanical loss or dielectric loss is uniformly distributed in the actuator and piezoelectric wafer.

\subsection{Piezoelectric Coupling}

For the actuator shown in Figure 1a, the driving voltage is applied in the piezoelectric ceramics, and the converse piezoelectric effect can be calculated by classical piezoelectric equations [31] by considering the mechanical loss and dielectric loss factors, which can be represented as follows (in a linear elastic range):

$$
\left\{\begin{array}{c}
S_{i}=s_{i_{j}}^{E} T_{j}+d_{i n} E_{n} \\
D_{m}=d_{m j} T_{j}+\varepsilon_{m n}^{T} E_{n}
\end{array}, i, j=1,2,3,4,5,6 ; m, n=1,2,3,\right.
$$

where $S_{i}$ is the strain component; $D_{m}$ is the electric displacement; $s_{i j}^{E}$ is the flexibility coefficient; $T_{j}$ is the stress component; $E_{n}$ is the electric field; $d_{i n}$ and $d_{m j}$ are the piezoelectric constants; $\varepsilon_{m n}^{T}$ is the free dielectric constant; and $i, j, m$, and $n$ are shortened subscripts representing different tensor orientations (more details can be seen in ref. [31]). In this paper, $s_{i j}^{E}$ would be a complex expression by including the loss factor $\eta_{s}$ in COMSOL. The boundary condition assumes that the outside area of the actuator is free.

\subsection{Initial and Boundary Conditions}

When the actuator operates in the endoscopic biopsy channel, because the contact area of the actuator and the permanent magnet orbit is very small, the main part of the heat on its surface is transferred to the atmosphere by convection. The equation of thermal convection can be expressed as [31]

$$
-k \frac{\partial T}{\partial n}=h_{p}\left(T^{4}-T_{c}^{4}\right),
$$

where $T_{c}$ is the ambient temperature, $h_{p}$ is the thermal convection dissipation coefficient (determined by the heat dissipation environment), $k$ is the heat conductivity, $n$ is the spatial vector, and $\partial T / \partial n$ represents the temperature gradient along the $\boldsymbol{n}$ direction.

Given that part of the heat is transmitted in the form of radiation, the effect of thermal radiation should also be taken into account. The expression is [32]

$$
-k \frac{\partial T}{\partial n}=\sigma A\left(T^{4}-T_{r}^{4}\right)
$$

where $\sigma$ is the Stefan-Boltzmann constant, $T_{r}$ is the environmental temperature, and $A$ is the radiant surface shape factor.

In order to calculate the temperature field distribution of the actuator, the initial temperature field state needs to be defined. The overall initial temperature is constant:

$$
T_{t=0}=T_{0},
$$

where $t$ is the working time and $T_{0}$ is the initial environmental temperature.

\subsection{Thermal Sources}

The transient thermal equilibrium equation can be represented as

$$
\rho C_{\mathrm{p}} \frac{\partial T}{\partial t}+\rho C_{\mathrm{p}} \mathbf{u} \cdot \nabla T=\nabla(k \nabla T)+Q
$$


where $T$ is the temperature, $t$ is the time, $\rho$ is the material density, $C_{\mathrm{p}}$ is the heat capacity, $k$ is the thermal conductivity, $\mathbf{u}$ is the velocity field, and $Q$ is the heat source-more heat sources can be added separately. The velocity field $\mathbf{u}$ is assumed to be null (ignoring acoustic fluid). For the heat source $Q$ in the experiment, it is made from the following parts: the mechanical and dielectric loss of the actuator and piezoelectric ceramic, represented as

$$
\left\{\begin{array}{c}
Q_{\mathrm{m}}=\eta_{s}\left(2 \pi f \cdot W_{\mathrm{h}}\right) \\
Q_{\mathrm{d}}=\eta_{e}\left(2 \pi f \cdot E^{2} \cdot \varepsilon_{\mathrm{p}}\right)
\end{array},\right.
$$

where $Q_{m}$ is the mechanical loss of the actuator body or the piezoelectric ceramics, and $Q_{d}$ is the dielectric loss of the piezoelectric ceramics. $W_{\mathrm{h}}$ is the mechanical energy density of the actuator in the vibration, $E$ is the electric field, and $\varepsilon_{\mathrm{p}}$ is the relative dielectric constant. $\eta_{\mathrm{s}}$ and $\eta_{\mathrm{e}}$ are the mechanical loss factor and dielectric loss factor, respectively. $Q_{\mathrm{m}}$ and $Q_{\mathrm{d}}$ can be calculated in terms of Equation (1), and the thermal calculation can then be obtained from Equation (3) according to the initial and boundary conditions.

\subsection{FEM Calculation}

The dimension parameters of the actuator are shown in Figure $1 \mathrm{~b}$ and the thickness of the glue layer (Epoxy resin), which is used for adhering the piezoelectric ceramics (PZT-8) and actuator body (Ferronickel), and conducting film (Polyimide) is set as $0.01 \mathrm{~mm}$. The material parameters of the actuator are shown in Table 1. The heat sources shown in Equation (4) determined that the analyzed model should be 3-D and include all the main structural parts. For solving the transient temperature field, the full method in COMSOL software is selected and the calculation time is set to 3 min with a time step of $1 \mathrm{~min}$. The mesh of the actuator is shown in Figure 3.

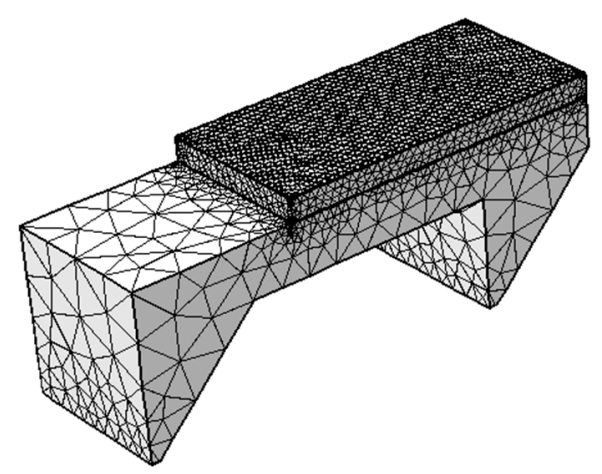

Figure 3. The mesh of the piezoelectric micro actuator. 
Table 1. Material parameters of the piezoelectric micro actuator.

\begin{tabular}{|c|c|c|c|c|c|c|c|c|c|c|c|}
\hline Materials & \multicolumn{6}{|c|}{ Young Modulus $\left(\times 10^{10} \mathrm{~N} / \mathrm{m}^{2}\right)$} & $\begin{array}{l}\text { Poisson } \\
\text { Ratio (1) }\end{array}$ & $\begin{array}{l}\text { Density } \\
\left(\mathrm{kg} / \mathrm{m}^{3}\right)\end{array}$ & $\begin{array}{c}\text { Heat Conductivity } \\
\text { Coefficient }(W /(m \cdot k))\end{array}$ & $\begin{array}{l}\text { Heat Capacity } \\
(\mathrm{J} /(\mathrm{kg} \cdot \mathrm{k}))\end{array}$ & $\begin{array}{l}\text { Damping } \\
\text { Ratio (1) }\end{array}$ \\
\hline Ferronickel & \multicolumn{6}{|c|}{12.3} & 0.27 & 8100 & 13 & 450 & 0.003 \\
\hline \multirow{6}{*}{ PZT-8 } & 12.06 & 5.35 & 5.15 & 0 & 0 & 0 & \multirow{6}{*}{0.31} & \multirow{6}{*}{7600} & \multirow{6}{*}{8.7} & \multirow{6}{*}{935} & \multirow{6}{*}{$0.01[32]$} \\
\hline & 5.35 & 12.06 & 5.15 & 0 & 0 & 0 & & & & & \\
\hline & 5.15 & 5.15 & 10.45 & 0 & 0 & 0 & & & & & \\
\hline & 0 & 0 & 0 & 3.13 & 0 & 0 & & & & & \\
\hline & 0 & 0 & 0 & 0 & 3.13 & 0 & & & & & \\
\hline & 0 & 0 & 0 & 0 & 0 & 3.46 & & & & & \\
\hline Polyimide & \multicolumn{6}{|c|}{0.3} & 0.25 & 1300 & 0.15 & 1100 & 0.01 [33] \\
\hline Epoxy resin & \multicolumn{6}{|c|}{0.1} & 0.38 & 980 & 0.2 & 1500 & 0.1 [34] \\
\hline
\end{tabular}




\section{Results and Discussion}

With a driving voltage of $200 \mathrm{~V}_{\mathrm{pp}}$ and a resonant frequency of $10.4 \mathrm{kHz}$, the actuator can move forward outside or inside the endoscopic channel (see Figure 4) and thus modulate the distance between the actuator and disease part, proving that the piezoelectric actuator and permanent magnet orbit can meet the size requirements of the endoscope and also be applicable for linear driving of the micro ultrasonic transducer or other dosing devices in the biopsy channel for drug penetration in an unresectable or non-abatable archenteric gastrointestinal tumor.
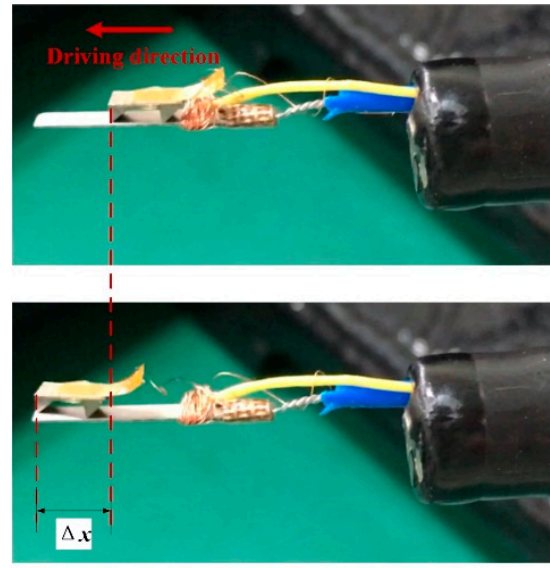

(a)

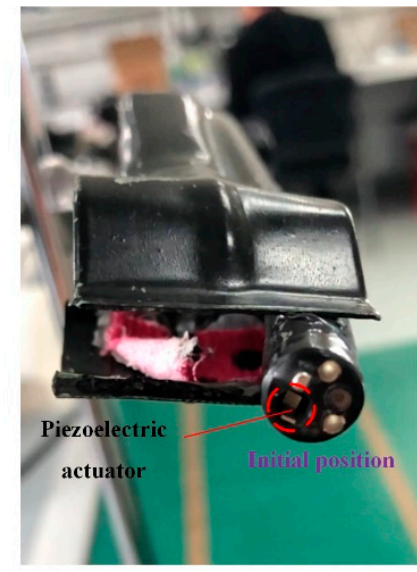

(b)

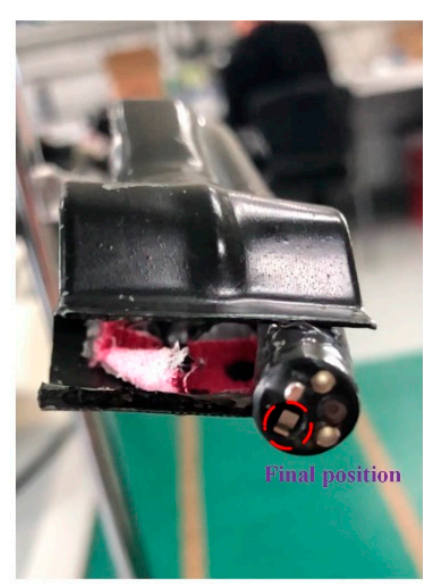

Figure 4. The motion process of the piezoelectric actuator: (a) outside the endoscopic biopsy channel (Video S2); (b) inside the endoscopic biopsy channel (Video S1).

To correlate the speed upon the application of driving voltage, duty ratio, and magnetic induction intensity, a performance test platform is established to obtain the motion performance of the piezoelectric actuator on the permanent magnet track. The permanent magnet orbit has an effective working distance of $10 \mathrm{~mm}$ and its motion process is given in Figure 5a. Shown in Figure 5b is the speed versus applied voltage performance of the actuator on the permanent magnet orbit, whose magnetic induction intensity is $145 \mathrm{mT}$. An upward trend in the speed with the increasing driving voltage is observed. A maximum speed of $168 \mathrm{~mm} / \mathrm{s}$ is achieved with a driving voltage of $200 \mathrm{~V}_{\mathrm{pp}}$ at $10.4 \mathrm{kHz}$. Meanwhile, a minimum speed of $25 \mathrm{~mm} / \mathrm{s}$ is achieved with a driving voltage of $120 \mathrm{~V}_{\mathrm{pp}}$. In addition, the amplitude of the leg is too small and it is difficult for the actuator to work stably when the driving voltage is lower than $120 \mathrm{~V}_{\mathrm{pp}}$, and the piezoelectric ceramics can be easily broken down when the driving voltage is higher than $200 \mathrm{~V}_{\mathrm{pp}}$. To characterize the effect of the magnetic induction intensity on the speed of the actuator, we measured the speed under various magnetic induction intensities and the obtained data are given in Figure 5c. The magnetic induction intensity can be changed by alcohol lamp heating permanent magnets and the grinding of permanent magnets. As can be seen from Figure $5 c$, the speed of the actuator under different magnetic induction intensities basically presents a linear distribution, and the speed of the actuator increases with the increase of the magnetic induction intensity. When the magnetic induction intensity of the permanent magnet orbit is 43 and $145 \mathrm{mT}$, the corresponding actuator speed is 41 and $168 \mathrm{~mm} / \mathrm{s}$, respectively. In this paper, because the permanent magnet orbit is ground to a thickness of $0.35 \mathrm{~mm}$ when the actuator is installed in the endoscope, its magnetic induction intensity is $43 \mathrm{mT}$.

According to the experimental measurement methods of Section 2, the maximum temperature of the front end of the actuator working in the endoscopic channel in the first 3 min is shown in Figure 6 for when the driving voltage is 200 V. From the figure, it is obvious that the endoscopic biopsy channel displayed the highest temperature because of the existence of the piezoelectric actuator being operated, while the temperature of the remaining regions was also affected by the operation of the piezoelectric actuator. Moreover, it shows that the temperature rises from $36.4{ }^{\circ} \mathrm{C}$ to $44.4^{\circ} \mathrm{C}$ with an 
increasing operation time, which is beyond the safe temperature of the human body. In particular, the temperature of the actuator is more than $42{ }^{\circ} \mathrm{C}$ just after $1 \mathrm{~min}$. As shown in Figure $7 \mathrm{a}$, the temperature field distribution of the actuator is obtained and the maximum temperature appears on the surface of the piezoelectric ceramics. Moreover, the results of Figure $7 \mathrm{~b}$ show that the calculated maximum temperature of the front end of the actuator (it is same measurement area as the experimental measurement area) rising curves corresponds to the experimental results, proving the effectiveness of this FEM method. These results all prove that the overheating problem really exists in the actuator. According to the theoretical analysis presented in Section 3, the temperature rise can be controlled by the driving voltage and duty ratio. Therefore, a study was carried out to characterize the influence of voltages and the duty ratio on the temperature rises of the actuator.

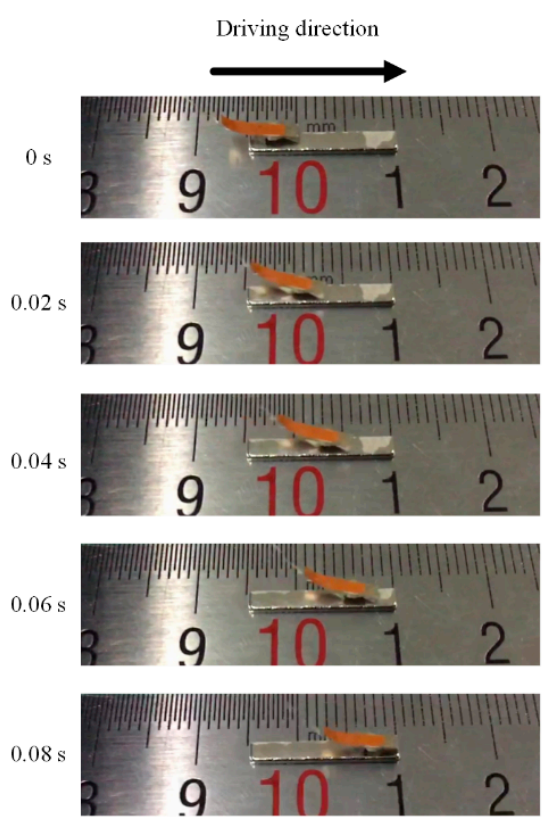

(a)
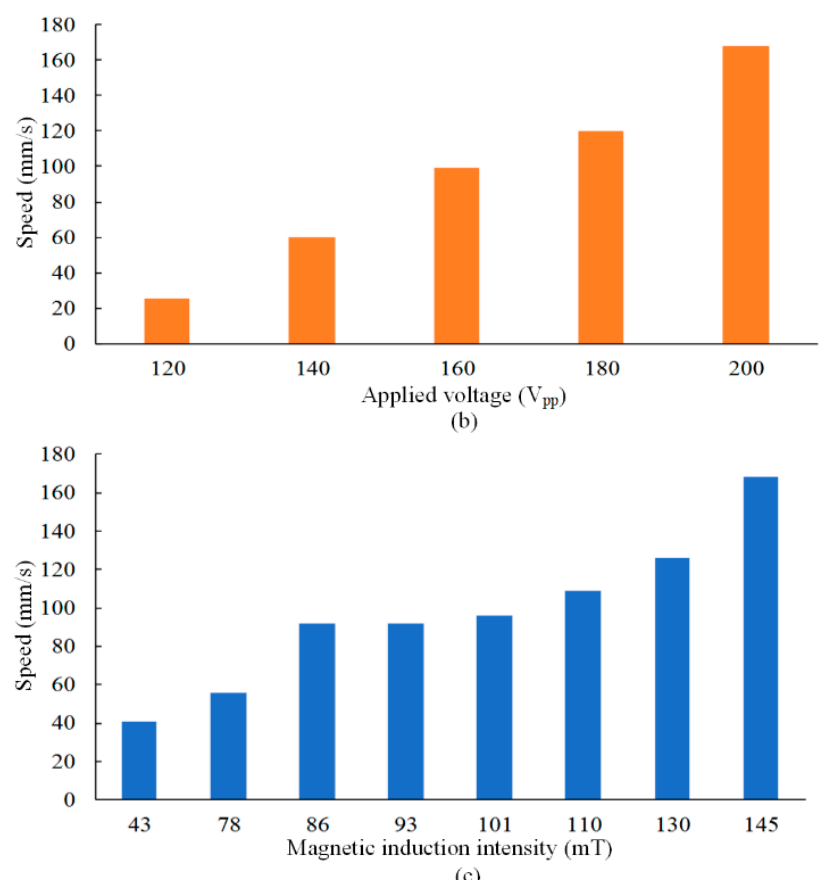

(c)

Figure 5. Performance of the actuator on the permanent magnet orbit: (a) the motion process; (b) speed versus applied voltage; (c) speed versus magnetic induction intensity.

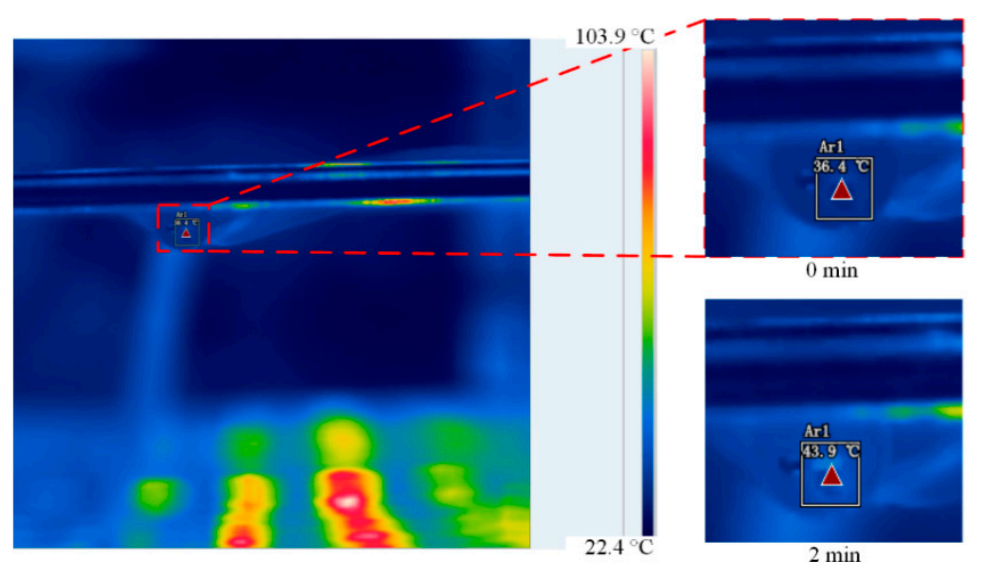

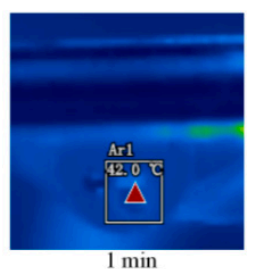

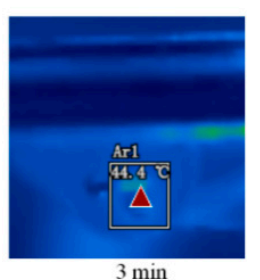

$3 \mathrm{~min}$

Figure 6. Temperature rise experimental results of the actuator working in the endoscopic channel when the driving voltage is $200 \mathrm{~V}_{\mathrm{pp}}$ in the first $3 \mathrm{~min}$. 


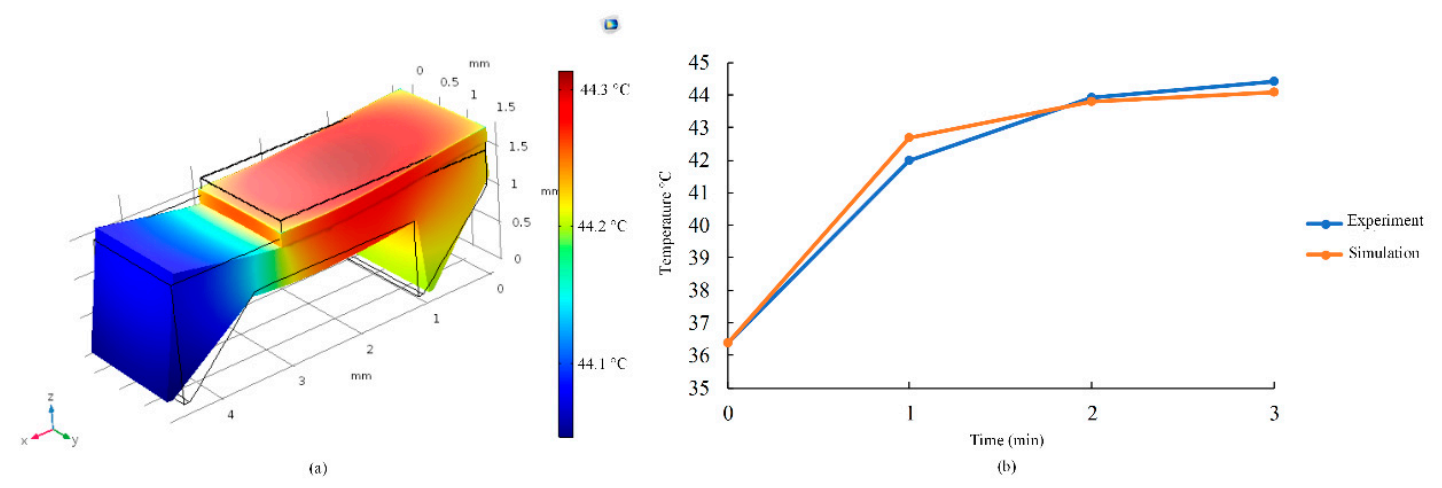

Figure 7. Temperature rise calculated results of the actuator working in the endoscopic channel when the driving voltage is $200 \mathrm{~V}_{\mathrm{pp}}$ in the first $3 \mathrm{~min}$ : (a) temperature field distribution; (b) a comparison of the simulation results and experimental results.

Figure 8 shows the dependence of the speed and temperature rises on the different duty ratios when the driving voltage is $200 \mathrm{~V}_{\mathrm{pp}}$ and the magnetic induction intensity of the permanent magnet orbit is $43 \mathrm{mT}$. As the duty ratio increases, the energy input to the actuator increases correspondingly, resulting in a corresponding increase in the actuator's speed, which shows an obvious linear relationship with the duty ratio. The speed of the actuator is $41 \mathrm{~mm} / \mathrm{s}$ when the duty ratio is $100 \%$. When the duty ratio is adjusted to $10 \%$, the actuator speed is greatly reduced to only $2.3 \mathrm{~mm} / \mathrm{s}$. With a further decreasing duty ratio, the actuator speed will continue to decrease to interrupt the working stability of the actuator.

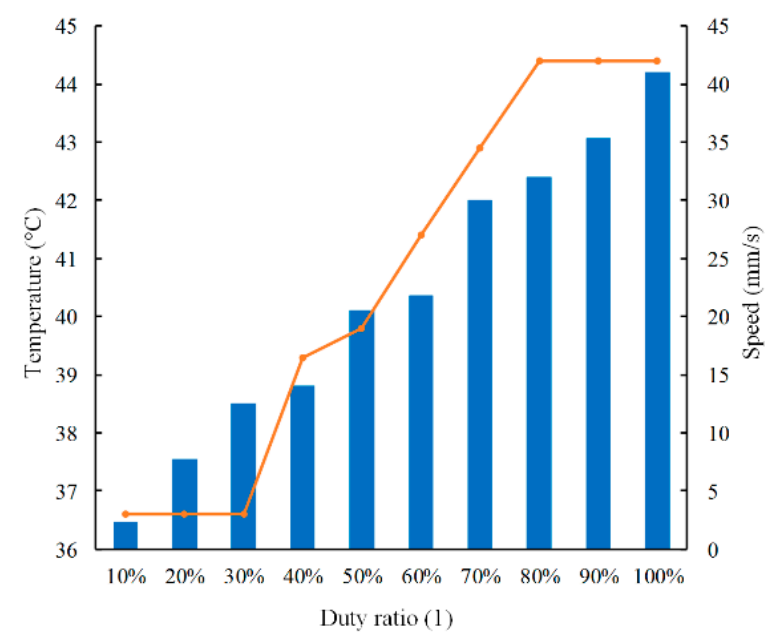

Figure 8. Speed (bar) and temperature rises (line) versus duty ratio performance of the actuator on the permanent magnet orbit.

Meanwhile, an upward trend in the temperature with an increasing duty ratio can be seen. As compared with a $100 \%$ duty ratio operation mode, a $60 \%$ duty ratio can more effectively decrease the temperature rise, as revealed by the corresponding temperatures of 44.4 to $41.4{ }^{\circ} \mathrm{C}$, respectively. When the duty ratio is adjusted to $30 \%$ or less, the temperature rises are greatly reduced to only $36.6^{\circ} \mathrm{C}$, which is close to the initial temperature $\left(36.4^{\circ} \mathrm{C}\right)$. Therefore, adjusting the driving voltage duty ratio has been proven to be a feasible method for preventing the temperature rising issue of the actuator in the biopsy channel with only a slight sacrifice of the actuator speed. It is noteworthy that the amplitude of the leg is too small and it is too difficult for the actuator to work stably when the driving voltage is lower than $200 \mathrm{~V}_{\mathrm{pp}}$ with a magnetic induction intensity of $43 \mathrm{mT}$, so the temperature rise control method that adjusts the driving voltage is not practical under this circumstance. 


\section{Conclusions}

A temperature rise control method of a piezoelectric actuator operated in an endoscopic biopsy channel has been studied in this paper. FEM based on COMSOL Multiphysics software has been proposed to achieve thermal analyses. The temperature distribution and its rising curves have been obtained by the FEM method. Both the simulated and experimental maximum temperatures are larger than the safety value when the driving voltage is $200 \mathrm{~V}_{\mathrm{pp}}$, which proves that the overheating problem really exists in the actuator. Furthermore, the results show that the calculated temperature rising curves correspond to the experimental results, proving the effectiveness of this FEM method. The experimental results demonstrate that the actuator speed increases with the increasing driving voltage and magnetic induction intensity of the permanent magnet orbit. However, when the actuator is installed in the endoscope, the permanent magnet orbit is ground to a thickness of $0.35 \mathrm{~mm}$, and its magnetic induction intensity is $43 \mathrm{mT}$, making it difficult to realize temperature control by adjusting the driving voltage. Therefore, only modulating the duty ratio of the actuator is applicable to control the temperature rises of the actuator. The experimental results illustrate that a $60 \%$ duty ratio can more effectively decrease the temperature rise than a continuous operation in the first $3 \mathrm{~min}$. When the duty ratio is adjusted to less than $30 \%$, the temperature rises are greatly reduced to only $36.6{ }^{\circ} \mathrm{C}$, which is close to the initial temperature $\left(36.4^{\circ} \mathrm{C}\right)$. Consequently, this work demonstrates that optimizing the duty ratio of the actuator can effectively control the temperature rises and well-maintain the speed of the actuator.

Supplementary Materials: The following are available online at http://www.mdpi.com/2076-3417/9/21/4499/s1, Video S1: The motion of actuator inside the biopsy channel, Video S2: The motion of actuator outside the biopsy channel.

Author Contributions: All the authors contributed to this study. P.Z.: formal analysis, investigation, and writing of the original draft; H.P.: conceptualization, funding acquisition, project administration, and supervision; J.Y.: investigation.

Funding: This research was funded by the Outstanding Youth Science Foundation of Jiangsu Province under grant number BK20180067 and the National Natural Science Foundation of China under grant number 51875280.

Acknowledgments: The authors are very grateful to the State Key Lab of Mechanics and Control of Mechanical Structures for providing experimental facilities and laboratory space.

Conflicts of Interest: The authors declare no conflicts of interest.

\section{References}

1. Chang, S.; Murdock, E.; Mao, Y.; Flueraru, C.; Disano, J. Stationary-fiber rotary probe with unobstructed $360^{\circ}$. Opt. Lett. 2011, 36, 4392-4394. [CrossRef] [PubMed]

2. Zhou, T.; Fu, D.; Chen, Y.; Chen, T.; Zhang, N. Ultrasonic Motor for Driving OCT Endoscopic. J. Vib. Mes. Diagn. 2013, 33, 737-740.

3. Su, Q.; Quan, Q.; Deng, J.; Yu, H. A Quadruped Micro-Robot Based on Piezoelectric Driving. Sensors 2018, 18, 810. [CrossRef] [PubMed]

4. Wang, S.; Housden, R.J.; Noh, Y.; Singh, A.; Lindenroth, L.; Liu, H.; Althoefer, K.; Hajnal, J.; Singh, D.; Rhode, K. Analysis of a Customized Clutch Joint Designed for the Safety Management of an Ultrasound Robot. Appl. Sci. 2019, 9, 1900. [CrossRef]

5. Takamaru, H.; Saito, Y.; Yamada, M.; Tsuruki, E.S.; Kinjo, Y.; Otake, Y.; Sakamoto, T.; Nakajima, T.; Matsuda, T.; So, E. Clinical impact of endoscopic clip closure of perforations during endoscopic submucosal dissection for colorectal tumors. Gastrointest. Endosc. 2016, 84, 494-502. [CrossRef]

6. Nakata, B.; Tendo, M.; Okuyama, M. Additional surgical resection after endoscopic mucosal dissection for early gastric cancer: A medium-sized hospital's experience. Int. J. Surg. 2016, 36, 335-441. [CrossRef]

7. Ma, M.X.; Bourke, M.J. Complications of endoscopic polypectomy, endoscopic mucosal resection and endoscopic submucosal dissection in the colon. Best Pr. Res. Clin. Gastroenterol. 2016, 30, 749-767. [CrossRef] 
8. Arima, S.; Sakata, Y.; Ogata, S. Evaluation of hemostasis with soft coagulation using endoscopic hemostatic forceps in comparison with metallic hemoclips for bleeding gastric ulcers: A prospective, randomized trial. J. Gastroenterol. 2010, 45, 501-505. [CrossRef]

9. Coumaros, D.; Tsesmeli, N. Active gastrointestinal bleeding: Use of hemostatic forceps beyond endoscopic submucosal dissection. World J. Gastroenterol. 2010, 16, 2061-2064. [CrossRef]

10. Kobara, H.; Mori, H.; Rafiq, K.; Fujihara, S.; Nishiyama, N.; Morishita, A.; Goda, Y.; Kanenishi, K.; Hata, T.; Masaki, T. Application of endoscopic hemostatic forceps for uterine cervical bleeding. Gastrointest. Endosc. 2015, 81, 234-235. [CrossRef]

11. Nelson, D.B.; Barkun, A.N.; Block, K.P. Endoscopic hemostatic devices. Gastrointest. Endosc. 2001, 54, 833-840. [CrossRef]

12. Ibrahim, M.; Elmikkawy, A.; Mostafa, I. Endoscopic treatment of acute variceal hemorrhage by using hemostatic powder TC-325: A prospective pilot study. Gastrointest. Endosc. 2013, 78, 769-773. [CrossRef] [PubMed]

13. Kume, K.; Yamasaki, M.; Yamasaki, T.; Yoshikawa, I.; Otsuki, M. Endoscopic hemostatic treatment under irrigation for upper-GI hemorrhage: A comparison of one third and total circumference transparent end hoods. Gastrointest. Endosc. 2004, 59, 712-716. [CrossRef]

14. Kerbel, R.S. Improving Conventional or Low Dose Metronomic Chemotherapy with Targeted Antiangiogenic Drugs. Cancer Res. Treat. 2007, 39, 150-159. [CrossRef]

15. Yuan, Y.; Shen, H.; Gu, F.Y. Multidisciplinary treatment with chemotherapy, targeted drug, and high-intensity focused ultrasound in advanced pancreatic carcinoma. Med. Oncol. 2012, 29, 957-961. [CrossRef]

16. Xin, Y.; Huang, Q.; Tang, J.Q.; Hou, X.Y.; Zhang, P.; Zhang, L.Z.; Jiang, G. Nanoscale drug delivery for targeted chemotherapy. Cancer Lett. 2016, 379, 24-31. [CrossRef]

17. Wang, L.; Sun, Y.; Zhao, B.; Zhang, H.; Yu, Q.; Yuan, X. Chemotherapy plus targeted drugs in conversion therapy for potentially resectable colorectal liver metastases: A meta-analysis. Oncotarget 2016, 7, 55732-55740. [CrossRef]

18. Onishi, K.; Sewa, S.; Asaka, K. Biomimetic microactuators based on polymer electrolyte/gold composite driven by low voltage. In Proceedings of the Thirteenth International Conference on Micro Electro Mechanical Systems, Miyazaki, Japan, 23-27 January 2000.

19. Boucaud, A.; Montharu, J.; Lebertre, M.; Patat, F.; Vaillant, L.; Machet, L. Biological effects of low frequency ultrasound on the skin. In Proceedings of the Ultrasonics Symposium, Caesars Tahoe, NV, USA, 17-20 October 1999.

20. Merino, G.; Kalia, Y.N.; Delgado-Charro, M.B.; Potts, R.O.; Guy, R.H. Frequency and thermal effects on the enhancement of transdermal transport by sonophoresis. J. Control Release 2003, 88, 85-94. [CrossRef]

21. Boucaud, A.; Machet, L.; Arbeille, B.; Machet, M.C. Clinical, histologic, and electron microscopy study of skin exposed to low-frequency ultrasound. Anat. Rec. 2001, 264, 114-119. [CrossRef]

22. Baisch, A.T.; Ozcan, O.; Goldberg, B.; Ithier, D.; Wood, R.J. High speed locomotion for a quadrupedal microrobot. Int. J. Robot. Res. 2014, 33, 1063-1082. [CrossRef]

23. Zhu, P.; Peng, H.; Yang, J.; Mao, T.; Sheng, J. A New Low-frequency Sonophoresis System Combined with Ultrasonic Motor and Transducer. Smart Mater. Struct. 2018, 27, 035021. [CrossRef]

24. Li, X.; Zhou, S. A novel piezoelectric actuator with a screw-coupled stator and rotor for driving an aperture. Smart Mater. Struct. 2016, 25, 35027. [CrossRef]

25. Shu, C.; Jin, J.; Zhang, J.; Wang, L. A novel traveling wave piezoelectric actuated tracked mobile robot utilizing friction effect. Smart Mater. Struct. 2017, 26, 35003.

26. Oh, C.H.; Choi, J.H.; Nam, H.J.; Bu, J.U.; Kim, S.H. Ultra-compact, zero-power magnetic latching piezoelectric inchworm motor with integrated position sensor. Sens. Actuators A Phys. 2010, 158, 306-312. [CrossRef]

27. Wang, T.; Lancee, C.; Beurskens, R.; Meijer, J.; Knapen, B.; Van Der Steen, A.F.; Van Soest, G. Development of a high-speed synchronous micro motor and its application in intravascular imaging. Sens. Actuators A Phys. 2014, 218, 60-68. [CrossRef]

28. Ahmadi, F.; McLoughlin, I.V.; Chauhan, S.; Ter-Haar, G.; McLoughlin, I.V.; Mc Loughlin, I. Bio-effects and safety of low-intensity, low-frequency ultrasonic exposure. Prog. Biophys. Mol. Biol. 2012, 108, 119-138. [CrossRef]

29. Taheri, H.; Hassen, A.A. Nondestructive Ultrasonic Inspection of Composite Materials: A Comparative Advantage of Phased Array Ultrasonic. Appl. Sci. 2019, 9, 1628. [CrossRef] 
30. Peng, H.; Yang, J.; Lu, X.; Zhu, P.; Wu, D. A light-weight surface milli-walker based on piezoelectric actuation. IEEE Trans. Ind. Electron. 2019, 66, 7852-7860. [CrossRef]

31. Zhao, C. Ultrasonic Motors Technologies and Applications; Springer: Berlin/Heidelberg, Germany, 2011.

32. Shin, C.; Hong, C.; Jong, W.; Kwon, O. Active vibration control of plates using positive position feedback control with PZT actuators. Noise Control Eng. J. 2016, 64, 279-289. [CrossRef]

33. Longun, J.; Iroh, J. Polyimide/substituted polyaniline-copolymer-nanoclay composite thin films with high damping abilities. J. Appl. Polym. Sci. 2013, 128, 1425-1435. [CrossRef]

34. Spanoudakis, J.; Young, R.J.; Young, R. Crack propagation in a glass particle-filled epoxy resin. J. Mater. Sci. 1984, 19, 473-486. [CrossRef]

(C) 2019 by the authors. Licensee MDPI, Basel, Switzerland. This article is an open access article distributed under the terms and conditions of the Creative Commons Attribution (CC BY) license (http://creativecommons.org/licenses/by/4.0/). 